\title{
Implementasi Nilai-Nilai Kemanusiaan dalam Kegiatan Korps Suka Rela Palang Merah Indonesia Unit Universitas Negeri Padang
}

\author{
Sri Lestari, Nurman S \\ Program Studi Pendidikan Pancasila dan Kewarganegaraan \\ Universitas Negeri Padang \\ E-mail: $\underline{\text { sriletari8796@yahoo.co.id }}$
}

\section{ABSTRAK}

Penelitian ini dilatarbelakangi oleh kurangnya partisipasi anggota KSR PMI Unit UNP dalam kegiatan yang dilakukan. Penelitian ini bertujuan untuk mendeskripsikan implementasi nilai-nilai kemanusiaan dalam kegiatan KSR PMI Unit UNP, faktor penghambat yang dihadapi, dan upaya yang dilakukan pengurus untuk mengatasi faktor penghambat tersebut. Penelitian ini menggunakan metode kualitatif dengan pendekatan studi kasus. Informan penilitian ini adalah pembina, pengurus, dan anggota KSR PMI Unit UNP serta mahasiswa yang bukan anggota KSR PMI Unit UNP dan masyarakat di lokasi KSR PMI Unit UNP mengadakan kegiatan. Jenis data yang digunakan adalah data primer dan data sekunder. Metode pengumpulan data melalui observasi, wawancara, dan studi dokumentasi. Uji keabsahan data menggunakan triangulasi sumber dan analisis data menggunakan model Miles dan Huberman. Hasil penelitian menemukan bahwa implementasi nilai-nilai kemanusiaan dalam kegiatan KSR PMI Unit UNP telah berjalan dengan baik namun masih perlu ditingkatkan lagi. Faktor penghambat yang dihadapi adalah komitmen dan dukungan dari anggota masih kurang, sumber daya dan waktu yang kurang memadai, dan adanya hambatan dari faktor eksternal. Sedangkan upaya yang dilakukan adanya evaluasi setiap selesai kegiatan, membuka arsip-arsip lama, membuat acara keakraban, mengajukan proposal ke pihak luar, iuran anggota serta adanya peminjaman perlengkapan kepada pihak luar.

Kata Kunci: Implementasi, Nilai-Nilai Kemanusiaan, Kegiatan KSR PMI Unit UNP

\section{ABSTRACT}

This research is backed by the lack of participation of members of the KSR PMI unit of UNP in activities conducted. This research aims to describe the implementation of humanitarian values in the activities of the KSR PMI unit UNP, the inhibitory factor, and the effort that the board has taken to overcome the inhibitory factor. This research used qualitative methods with a case study approach. The research subjects where contractor, manager, and member of the KSR PMI unit UNP and collage students who are not members of the KSR PMI unit UNP and the community in the location of the KSR PMI unit UNP held activities. The type of data used is primary data and secondary data. The method of collecting data through observation, interviews, and documentation studies. The validity of 
data using source triangulation and data analysis using the Miles and Huberman models. The results found that the implementation of humanitarian values in the activities of the KSR PMI unit UNP has been running well but still need to be improved again. The inhibitory factor that is faced is the commitment and support of the members is still lacking, resources and time is insufficient, and the presence of barriers from external factors. Meanwhile, the effort to complete the evaluation of each activity, open old archives, make the event familiarity, submit proposals to outside parties, member dues and the loan of equipment to outside parties.

Keywords : Implementation, Humanitarian values, Activities KSR PMI Unit UNP

This work is licensed under the Creative Commons Attribution-ShareAlike 4.0 International License. (2019 by author and Universitas Negeri Padang.

\section{PENDAHULUAN}

KSR PMI Unit UNP telah berkontribusi mengimplementasikan nilai kemanusiaan dalam berbagai kegiatan. Kegiatan kemanusiaan yang dilakukan oleh KSR PMI Unit UNP adalah donor darah, tanggap darurat bencana, tim pertolongan pertama, dan bakti palang merah. Namun berdasarkan pengamatan penulis, walau anggota KSR PMI Unit UNP sudah memahami nilai-nilai kemanusiaan dan memiliki kegiatan yang mendukung tetapi partisipasi anggotanya masih kurang dalam kegiatan tersebut.

Dengan adanya permasalahan di atas, apabila dibiarkan saja maka partisipasi anggota dalam mengimplementasikan nilai kemanusiaan juga akan berkurang. Dan bisa jadi KSR PMI Unit PMI tidak lagi berjalan sebagaimana fungsinya. Selain itu, peranan anggota KSR PMI Unit UNP dalam menerapkan nilai kemanusiaan sebagai warga negara Indonesia juga akan berangsur menghilang. Sehingga akan menimbulkan ketidakpedulian antar sesama dan sikap individualis semakin menguat. Jika sikap individualis sudah menguat maka sikap kebersamaan akan hilang dan bisa menimbulkan perpecahan atau konflik.

Sebagaimana diketahui bahwa KSR PMI memiliki peranan dalam pelaksanaan nilai-nilai pancasila sila kedua yaitu nilai kemanusiaan. Dalam kegiatan yang dilakukan terdapat kegiatan-kegiatan kemanusiaan yang dapat memberikan manfaat bagi yang menerimanya. Begitu pula dengan orang-orang yang tergabung di dalam organisasi ini, tentunya menjadi orangorang yang luar biasa karena telah bergabung dan menjalankan kegiatankegiatan kemanusiaan yang tentunya membawa manfaat bagi masyarakat luas. Tidak hanya memberikan manfaat bagi diri sendiri tetapi juga untuk orang lain yang dilakukan secara sukarela untuk mengurangi penderitaan yang dirasakan oleh sesama tanpa membeda-bedakan.

$$
\text { Penelitian Ashari }
$$
menemukan bahwa PMI memiliki peranan dalam mengimplementasikan nilai-nilai kemanusiaan sila kedua Pancasila serta membawa manfaat yang besar untuk masyarakat atas bantuan yang diberikan. Peranan dalam melaksanakan nilai-nilai kemanusiaan ternyata tidak hanya dapat dilakukan di PMI tetapi juga bisa dilakukan dalam organisasi lain 
maupun di sekolah. Sebagaimana yang ditemukan oleh Khoirunnisak (2017) bahwa kegiatan yang dilakukan OPSHID terdapat implementasi nilai Pancasila yang berupa do'a bersama, santunan, rumah layak huni, dan jelajah desa sedangkan kendala yang dihadapi mudah untuk diatasi karena anggotanya mempunyai kesadaran bertanggung jawab.

Susanti (2013) yang menemukan bahwa dalam kegiatan ibu-ibu PKK dapat ditemui adanya implementasi nilai kemanusiaan yang dilaksanakan oleh anggota dan masyarakat serta yang menjadi faktor penghambat adalah ketua PKK tidak menjalankan tugas, kesadaran antara hak dan kewajiban. Dan Abduh dan Taniredja (2017) juga menemukan bahwa pengembangan sila kedua diperlukan contoh yang baik bagi siswa untuk bisa diikuti. Sehingga siswa memiliki kepribadian mandiri, peduli kepada sesama, menjaga lingkungan, dan menjaga semangat kebersamaan (Rianto, 2016).

Berdasarkan penjabaran di atas, ada beberapa hal yang membedakan dengan penelitian yang dilakukan. Jika penelitian sebelumnya hanya menjelaskan kegiatan yang dilaksanakan merupakan cerminan pelaksanaan nilai-nilai pancasila, namun dalam penelitian ini lebih mengidentifikasikan setiap butir nilainilai kemanusiaan dalam sila kedua Pancasila. Sehingga dapat diketahui bahwa setiap butir nilai kemanusiaaan telah dilaksanakan atau belum. Selain itu dalam penelitian ini dijabarkan mengenai hambatan yang dihadapi dalam mengimplementasikan nilai kemanusiaan dan upaya mengatasinya. Oleh karena itu, penelitian ini bertujuan untuk
Volume 2 No. 42019

mengetahui implementasi nilai kemanusiaan dalam kegiatan KSR PMI Unit UNP, faktor penghambat serta upaya untuk mengatasi faktor penghambat tersebut. Sehingga dengan dilakukannya penelitian ini dapat meningkatkan kesadaran anggota akan pentingnya manfaat nilai kemanusiaan dan mengamalkan nilai kemanusiaan dalam kehidupan seharihari.

\section{METODE PENELITIAN}

Penelitian ini menggunakan metode kualitatif dengan pendekatan studi kasus. Lokasi penelitian yang dipilih adalah KSR PMI Unit UNP. Informan penelitian ini adalah pembina, pengurus, dan anggota KSR PMI Unit UNP serta mahasiswa yang bukan anggota KSR PMI Unit UNP dan masyarakat di lokasi KSR PMI Unit UNP mengadakan kegiatan yang dipilih dengan purposive sampling.

Data yang dikumpulkan adalah data primer dan data sekunder. Data primer dalam penelitian ini adalah bagaimana implementasi nilai kemanusiaan dalam Kegiatan KSR PMI Unit UNP, faktor penghambat dan upaya mengatasinya yang didapatkan dari informan penelitian dari hasil wawancara dan hasil observasi. Sedangkan data sekunder dalam penelitian ini adalah dokumendokumen yang berkaitan dengan penelitian yang didapatkan dari program kerja KSR PMI Unit UNP, daftar hadir anggota KSR PMI Unit UNP yang ikut kegiatan, laporan pertanggungjawaban DPH KSR PMI Unit UNP, dokumentasi kegiatan KSR PMI Unit UNP, data base anggota KSR PMI Unit UNP, dan ART KSR PMI Unit UNP. Teknik pengumpulan data menggunakan observasi, wawancara, 
dan studi dokumentasi. Sedangkan uji keabsahan data menggunakan triangulasi sumber dengan membandingkan hasil observasi dengan wawancara. Dan teknik analisis data menggunakan model Miles dan Huberman berupa pengumpulan data, reduksi data, penyajian data, dan penarikan kesimpulan/verifikasi.

\section{HASIL DAN PEMBAHASAN}

\section{Implementasi Nilai-Nilai Kemanusiaan dalam Kegiatan KSR PMI Unit UNP}

Dari hasil penelitian diketahui bahwa kegiatan yang dilakukan oleh KSR PMI Unit UNP mencerminkan nilai-nilai kemanusiaan. Implementasi nilai-nilai kemanusiaan bagi anggota KSR PMI Unit UNP menjadi hal yang tidak sulit, karena kegiatan-kegiatan yang dilakukan mengandung nilainilai kemanusiaan terutama dalam kegiatan kemanusiaan. Butir-butir implementasi sila kedua Pancasila yaitu nilai kemanusiaan yang dilaksanakan dalam KSR PMI Unit UNP adalah mengakui persamaan derajat, persamaan hak dan kewajiban, saling mencintai, tenggang rasa, tidak semena-mena, menjunjung tinggi nilai-nilai kemanusiaan, dan gemar melakukan kegiatan kemanusiaan.

\section{Pengakuan Persamaan Derajat, Persamaan Hak dan Kewajiban Antar Sesama Manusia}

Implementasi

nilai-nilai

kemanusiaan dalam kegiatan KSR PMI Unit UNP yaitu adanya sikap tidak membeda-bedakan dalam kegiatan yang dilaksanakan, setiap anggota boleh berpartisipasi dalam kegiatan. Dan tidak adanya perlakuan yang berbeda kepada yang mengikuti kegiatan baik itu laki-laki maupun perempuan boleh turun ke lapangan untuk membantu sesama.

Hal ini sependapat dengan yang dikemukakan Srijanti bahwa warga negara dapat menghargai manusia dengan segala kelebihan dan kekurangan yang dimilikinya, setiap manusia memiliki hak untuk hidup secara layak dan memakai sopan santun dalam bergaul dengan sesamanya (Srijanti dkk, 2011).

Dengan demikian KSR PMI Unit UNP telah mengimplementasikan butir pertama implementasi nilai kemanusiaan dalam kehidupan seharihari. Sebagaimana yang dikatakan oleh Ananda (2012) bahwa salah satu butir pengamalan sila kedua Pancasila adalah adanya pengakuan persamaan derajat, persamaan hak dan kewajiban antar sesama manusia. Selain itu telah mencerminkan nilai kemanusiaan yang terdapat dalam PMI yaitu tidak membeda-bedakan korban yang diberikan bantuan.

Senada dengan yang dikatakan oleh Sapta (2009) bahwa prinsip kemanusiaan mengandung makna bahwa setiap kegiatan yang dilakukan harus atas dasar keinginan mencegah dan mengatasi penderitaan sesama manusia, tanpa membeda-bedakan korban yang diberikan bantuan sehingga akan menumbuhkan rasa persahabatan, kerjasama, dan perdamaian.

\section{Sikap Saling Mencintai Sesama Manusia}

Sikap saling mencintai dapat ditunjukkan dari sikap anggota yang rela memberikan dan mengorbankan darahnya untuk diberikan kepada yang membutuhkan darah secara suka rela sebagai wujud sikap saling mencintai antar sesama. Bahkan juga 
membantu mencarikan pendonor untuk memenuhi kebutuhan darah yang diperlukan. Selain itu adanya pengorbanan waktu dan tenaga untuk memberikan bantuan kepada korban bencana dan korban yang sakit guna mengurangi penderitaan yang dirasakan oleh sesama.

Dikatakan oleh Srijanti bahwa salah satu butir implementasi sila kedua yaitu pancasila adalah saling mencintai sesama manusia yang dimaknai sebagai keinginan untuk mendapatkan sesuatu dan keinginan untuk memiliki yang bila perlu berkorban untuk mempertahankannya (Srijanti dkk, 2011). Dengan demikian KSR PMI Unit telah mengimplementasikan butir kedua implementasi nilai kemanusiaan dalam kehidupan sehari-hari.

\section{Sikap Tenggang Rasa}

Sikap tenggang rasa dapat terlihat dalam interaksi antara anggota dengan masyarakat. Anggota tidak memaksakan kehendaknya kepada masyarakat untuk mengikuti kegiatan. Jadi masyarakat yang mengikuti kegiatan hanya yang mau berpartisipasi saja sedangkan yang tidak mau maka tidak dipaksa untuk berpartisipasi.

Sehingga dapat diketahui bahwa rasa saling hormat dan menghormati masih terlihat dalam kegiatan yang dilakukan. Terlihat adanya sikap menghargai keputusan orang lain. Dan tidak adanya pemaksaan kehendak kepada orang lain.

Rahayu (2014) kemanusiaan yang adil dan beradab mengandung suatu kesadaran nilai tentang kesadaran moral dan tingkah laku yang dimiliki oleh manusia berdasarkan nurani terhadap diri sendiri, manusia lain, maupun lingkungannya.

Dengan demikian dapat disimpulkan bahwa implementasi nilai kemanusiaan butir dua yaitu mengembangkan sikap tenggang rasa dalam kegiatan KSR PMI Unit UNP dilakukan dengan menghargai setiap keputusan seseorang dan tidak memaksakan kehendak kepada orang lain.

\section{Sikap Tidak Semena-mena Terhadap Orang Lain}

Sikap tidak semena-mena terhadap orang lain terlihat dari setiap tindakan yang dilakukan terlebih dahulu ditanyakan dan diberitahukan kepada korban. Jadi tidak sembarangan memberikan tindakan terhadap para korban. Dengan begitu tindakan yang diberikan tidak akan menyinggung perasaan korban dan lebih tepat sasaran. Sehingga bantuan yang diberikan tetap memperhatikan martabat manusia untuk memperoleh kehidupan yang layak dan terhormat.

Senada dengan yang dikatan Srijanti (2011: 27-28) salah satu implementasi nilai kemanusiaan butir empatnya adalah tidak semena-mena terhadap orang lain yang menghendaki agar manusia tidak sewenang-wenang dalam menjalani kehidupan karena manusia memiliki martabat dan berhak memperoleh kehidupan yang layak dan terhormat.

Dengan demikian sikap tidak semena-mena terhadap orang lain terlihat dalam tindakan yang dilakukan oleh anggota dalam memberikan bantuan terlebih dahulu ditanyakan kepada korban. Maka dapat disimpulkan bahwa KSR PMI Unit UNP telah mengimplementasikan butir kedua implementasi nilai 
kemanusiaan dalam kehidupan seharihari.

\section{Menjunjung Tinggi Nilai-nilai Kemanusiaan}

Setiap kegiatan yang dilakukan oleh KSR PMI Unit UNP selalu terselip nilai-nilai kemanusiaan di dalamnya. Terutama dalam kegiatan-kegiatan yang bersifat kemanusiaan. Karena pada dasarnya KSR PMI Unit UNP merupakan organisasi yang bergerak dibidang kemanusiaan. Sehingga menjunjung tinggi nilai-nilai kemanusiaan menjadi pedoman dalam setiap melakukan kegiatan.

Setiap menjalankan tugas KSR PMI Unit UNP berpegang teguh pada prinsip-prinsip dasar gerakan palang merah dan bulan sabit merah internasional. Adapun prinsip pertamanya adalah kemanusiaan yang berarti setiap kegiatan kemanusiaan yang dilakukan diberikan tanpa diskriminasi untuk mengurangi penderitaan sebagai sesama manusia (UU No.1/2018 Tentang Kepalangmerahan).

Winarno (2012) mengatakan nilai kemanusiaan yang adil dan beradab bermakna adanya kesadaran sikap serta perilaku atas tuntutan hati nurani yang sesuai dengan nilai moral dalam kehidupan bersama. Manusia sebagai makhluk Tuhan memiliki kesamaan derajat yang harus mendapatkan perlakuan sesuai dengan harkat dan martabatnya.

Dengan demikian sebagai warga negara yang menjalankan kehidupan harus menjunjung tinggi nilai-nilai kemanusiaan. Dalam menjalannya didukung dengan program kerja yang dilakukan oleh KSR PMI Unit UNP. Dimana dalam setiap kegiatannya di dasari oleh prinsip kemanusiaan yang tentunya juga mendukung pelaksanaan nilai-nilai kemanusiaan dalam kehidupan sehari-hari. Sehingga dapat dikatakan bahwa KSR PMI Unit UNP telah menjunjung tinggi nilai-nilai kemanusiaan.

\section{Gemar Melakukan Kegiatan Kemanusiaan}

KSR PMI Unit UNP sebagai organisasi yang bergerak dibidang kemanusiaan telah melakukan berbagai kegiatan kemanusiaan. Kegiatan kemanusiaan yang dilakukan adalah donor darah, penanggulangan bencana, bakti palang merah, dan tim pertolongan pertama.

UU No.1/2018 Tentang Kepalangmerhan menyebutkan bahwa tugas dari PMI beberapa diantaranya adalah memberikan bantuan pelayanan darah, memberikan bantuan dalam bencana, memberikan pelayanan kesehatan dan sosial (UU No. $\quad 1 / 2018 \quad$ Tentang Kepalangmerahan).

Berdasarkan hasil penelitian diketahui bahwa KSR PMI Unit UNP telah melakukan kegiatan kemanusiaan yang disebutkan dalam UU Nomor 1 Tahun 2018 Tentang Kepalangmerahan. Dengan melakukan tugas-tugas tersebut tentunya KSR PMI Unit UNP menjadi organisasi yang gemar melakukan kegiatan kemanusiaan. Karena pada dasarnya organisasinya bergerak dibidang kemanusiaan.

Kegiatan yang dilakukan tanpa membeda-bedakan dan bertujuan untuk mengurangi penderitaan sesama. Seperti kegiatan penanggulangan bencana baik dilakukan melalui penggalangan dana ataupun membantu langsung di lokasi yang terdampak bencana. Saling membantu meringankan beban yang diderita oleh orang lain. Memberikan 
bantuan dalam bentuk tenaga maupun materi. Bantuan yang diberikan bentuk materi didapatkan dari penggalangan dana dan iuran anggota. Senada dengan yang dikatakan Notonegoro (dalam Winarno, 2012) bahwa nilai kebaikan adalah nilai yang berasal dari kehendak manusia.

Pada dasarnya dalam melakukan kegiatan kemanusiaan tidaklah membeda-bedakan dalam memberi pertolongan. Senada dengan yang dikatakan oleh Sapta (2009) bahwa prinsip kemanusiaan mengandung makna bahwa setiap kegiatan yang dilakukan harus atas dasar keinginan mencegah dan mengatasi penderitaan sesama manusia, tanpa membedabedakan korban yang diberikan bantuan sehingga akan menumbuhkan rasa persahabaan, kerjasama, dan perdamaian. Namun ternyata masih ada anggota yang pilih-pilih dalam mengikuti kegiatan seperti tim pertolongan pertama.

\section{Faktor Penghambat Implementasi Nilai-nilai Kemanusiaan Dalam Kegiatan KSR PMI Unit UNP}

Faktor yang menghambat implementasi nilai-nilai kemanusiaan dalam kegiatan KSR PMI Unit UNP adalah motivasi yang tidak sesuai dengan kenyataan. Motivasi anggota masuk dalam organisasi tidak sesuai dengan keaktifan dalam organisasi. Adanya motivasi untuk menambah wawasan dan membantu sesama namun setelah bergabung keorganisasi hal tersebut cenderung kurang terlihat. Bahkan dalam kegiatan-kegiatan yang dilakukan ternyata kurang aktif.

Selain itu kurangnya partisipasi anggota karena berbagai alasan. Baik karena perkuliahan, kegiatan kuliah, Praktik Lapangan Kependidikan, pulang kampung, adanya yang pilihpilih dalam mengikuti kegiatan, adanya yang anggota yang tidak berani memberikan penanganan, kegiatan dilakukan dibulan ramadahan, kegiatan dilakukan saat hari libur, dan lokasi kegiatan yang lumayan jauh.

Sabatier (dalam Purwanti, 2015: 19-20) mengatakan bahwa ada enam variabel suatu implementasi akan mengalami keberhasilan atau kegagalan, dua diantaranya yaitu adanya komitmen dari pelaku kebijakan dan adanya dukungan dari para pelaku kebijakan.

Berdasarkan hasil penelitian dapat disimpulkan komitmen dan dukungan dari anggota masih kurang dalam kegiatan-kegiatan yang dilakukan oleh KSR PMI Unit UNP. Sehingga hal ini perlu di atas agar tidak berlarut-larut dan bisa menyebabkan suatu kegagalan.

Hambatan lain yang dihadapi dalam implementasi nilai-nilai kemanusiaan dalam kegiatan KSR PMI Unit UNP adalah kurang konsisten terhadap waktu dan bentroknya kegiatan dengan perkuliahan. Waktu yang dimiliki anggota tidak sesuai dengan jadwal kegiatan dikarenakan harus menyelesaikan kegiatan yang lain seperti kuliah ataupun membuat tugas. Bahkan jika kegiatan yang dilakukan bertepatan hari libur pun sebagian anggota lebih memilih untuk pulang kampung dari pada mengikuti kegiatan.

Kurangnya dana dalam pelaksanaan suatu kegiatan yang menjadi hal klasik dalam kegiatan KSR PMI Unit UNP. Dana yang diberikan oleh pihak kampus pun diberikan setelah akhir kepengurusan. Sehingga sebelum dana tersebut cair harus cari 
dana lain dulu. Bahkan setelah dana dari kampus tersebut cair tetapi tidak mencukupi semuanya sehingga mengalami kesulitan dalam manajemen keuangannya.

Faktor penghambat implementasi nilai-nilai kemanusiaan dalam kegiatan KSR PMI Unit UNP yang lain adalah kurang lengkapnya perlengkapan seperti tandu dan bed yang menunjang kegiatan di lapangan. Karena tandu yang dimiliki hanya dua buah dan yang satu dalam keadaan rusak. Serta dukungan dari pihak kampus yang masih setengahsetengah. Pihak kampus yang memberikan izin kegiatan namun dalam pelaksanaannya kurang didukung. Seperti adanya peminjaman perlengkapan ke pihak kampus, terkadang sebenarnya perlengkapan tersebut ada namun tidak dipinjamkan. Dan ada kalanya dipinjamkan namun dalam keadaan yang kurang baik, padahal ada yang lebih baik dari itu.

Senada dengan Hogwood dan Gunn (dalam Purwanti, 2015) mengatakan hambatan yang dihadapi dalam implementasi dua diantaranya adalah hambatan dari kondisi eksternal, sumber daya dan waktu tersedia tidak memadai. Dengan demikian dari hasil penelitian diketahui bahwa faktor penghambat implementasi nilai-nilai kemanusiaan dalam kegiatan KSR PMI Unit UNP adalah waktu yang dimiliki oleh anggota kurang memadai dengan kegiatan yang dilakukan. Dan adanya hambatan dari faktor eksternal seperti kurangnya dana, perlengkapan yang kurang, dan dukungan dari pihak kampus yang masih setengahsetengah.

\section{Upaya Pengurus KSR PMI Unit UNP Mengatasi Faktor Penghambat Implementasi Nilai- nilai Kemanusiaan}

Kendala-kendala yang dihadapi dalam kegiatan yang dilakukan menjadi faktor penghambat implementasi nilai-nilai kemanusiaan. Untuk mengatasi hal tersebut banyak upaya yang telah dilakukan oleh pengurus KSR PMI Unit UNP. Adapun upaya-upaya yang dilakukan adalah adanya evaluasi setiap selesai kegiatan, membuka arsip-arsip lama, banyak bertanya pada anggota luar biasa, peran pengurus mengajak anggota untuk aktif dengan membuat acara keakraban, menghubungi king dan queen per angkatan untuk mengajak teman-teman seangkatannya dapat berpartisipasi dalam kegiatan.

Sedangkan dalam hal
kekurangan dana upaya yang dilakukan pengurus dengan mengajukan proposal ke pihak luar dan iuran anggota. Iuran anggota ini bisa didapatkan juga dari anggota luar biasa karena kebanyakan sudah bekerja dan memiliki pekerjaan. Dan untuk perlengkapan dilakukan peminjaman kepada pihak luar seperti KSR Unit lain maupun PMR binaan, UKM lain maupun pihak kampus. Peminjaman ditujukan kepada pihakpihak yang memiliki perlengkapan yang dibutuhkan.

Selain itu dalam kegiatan penggalangan dana upaya yang dilakukan untuk lebih memperhatikan situasi dan kondisi saat penggalangan dana dan memberikan penjelasan lebih rinci dampak yang terjadi akibat bencana agar pemberi sumbangan lebih tertarik untuk menyumbang. Dan tetap memperhatikan surat-surat 
perizinan lokasi penggalangan dana agar menghindari hal-hal yang tidak diinginkan.

\section{KESIMPULAN}

Berdasarkan hasil penelitian dan pembahasan menunjukkan bahwa KSR PMI Unit UNP telah melaksanakan nilai kemanusiaan dalam setiap kegiatan yang dilakukan meliputi; tidak membeda-bedakan perlakuan antar sesama, pengorbanan yang diberikan baik darah, waktu dan tenaga untuk membantu sesama, menghargai keputusan dan tidak memaksakan kehendak kepada orang lain, tindakan yang diberikan terlebih dahulu ditanyakan dan diberitahukan kepada korban, menyelenggarakan berbagai kegiatan kemanusiaan. Dengan demikian diketahui bahkan pelaksanaan nilai kemanusiaan dalam kehidupan sehari-hari dapat dilakukan dengan baik oleh anggota KSR PMI Unit UNP. Tetapi masih diperlukan peningkatan dalam komitmen dan dukungan anggota, pembagian waktu, dukungan pihak kampus maupun pencarian dana dan perlengkapan sehingga hasil kegiatan yang dicapai dapat lebih baik lagi. Ini menjadi faktor penghambat yang perlu dibenahi agar keberhasilan kegiatan dapat lebih baik. Dan telah berbagai upaya yang dilakukan untuk mengatasinya seperti adanya evaluasi setiap selesai kegiatan, membuka arsip-arsip lama, membuat acara keakraban, mengajukan proposal ke pihak luar, iuran anggota serta adanya peminjaman perlengkapan kepada pihak luar.

\section{DAFTAR PUSTAKA}

Abduh, M dan Tukiran T. (2017). Pengembangan Nilai-nilai Sila
II Pancasila Pada Peserta Didik Kelas VI Sekolah Dasar. Scholaria, Vol. 7, No. 2, Mei 2017. Ananda, Azwar. (2012). Pendidikan Kewarganegaraan (PKn) Pendidikan Karakter Bangsa Dan Strategi Pembelajaran Nilai. Padang: UNP Press.

Ashari, Alfiantika Febrian. (2016). Analisis Peranan Palang Merah Indonesia (PMI) Kota Madiun Dalam Mengimplementasikan Nilai-Nilai Pancasila Sila Kedua. Citizenship: Jurnal Pancasila dan Kewarganegaraan, Vol. 4, No. 2,

Khoirunnisak, A. (2017). Implementasi Nilai-Nilai Pancasila Dalam Kegiatan Dewan Pimpinan Cabang Organisasi Pemuda Shiddiqiyyah (OPSHID) Kecamatan Kabuh Kabupaten Jombang. Kajian Moral dan Kewarganegaraan, Vol. 5, No. 03. Purwanto, Erwan A, dan Dyah R. (2015). Implementasi Kebijakan Publik: Konsep dan Aplikasinya di Indonesia. Yogyakarta: Gava Media.

Rahayu, Ani Sri. (2014). Pendidikan Pancasila $\mathcal{E}$ Kewarganegaraan (PPKn). Jakarta: Bumi Aksara.

Rianto, Hadi. (2016). Implementasi Nilai Kemanusiaan Yang Adil dan Beradab di Lingkungan Sekolah. Sosial Horizon: Jurnal Pendidikan Sosial, Vol. 3, No. 1.

Sapta, Seven Audi. (2009). Kenali PMI. Jakarta: PMI.

Srijanti, dkk. (2011). Pendidikan Kewarganegaraan di Perguruan Tinggi: Mengembangkan Etika Berwarga Negara. Jakarta: Salemba Empat. 
220 |Strategi Penyelesaian..

Undang-undang Republik Indonesia Nomor 1 Tahun 2018 Tentang Kepalangmerahan.

Winarno. (2012). Paradigma Baru Pendidikan Kewarganegaraa: Panduan Kuliah di Perguruan Tinggi. Jakarta: Bumi Aksara. 